\title{
Lineament Extraction from Southern Chitradurga Schist Belt using Landsat TM, ASTERGDEM and Geomatics Techniques
}

\author{
Kiran Raj.S \\ Department of Geology, Central University of \\ Karnataka, Kadaganchi \\ Gulbarga-585311
}

\author{
S.A.Ahmed \\ Department of Geology, Central University of \\ Karnataka, Kadaganchi \\ Gulbarga-585311
}

\begin{abstract}
Lineament extraction from satellite data has been the most widely used applications in geology. Recent developments in digital image processing have made the extraction of lineament in semi-automatic to fully automatic approaches possible. In this study, a fully automatic approach, consisting of a combination of edge-line detection Canny algorithm was used, a grid operator designed for the analysis of potential field data was applied to a digital elevation model for the detection of lineaments using Landsat TM and ASTERGDEM images. At different orientations, by simulating topographic illumination under varied light directions, lineaments can be enhanced and mapped. The lineaments extracted show almost a similar orientation and differences in density. Combinations of four shaded relief images within the four sun azimuth directions of light sources at $0^{\circ}, 45^{\circ}, 90^{\circ}$ and $135^{\circ}$ give $\mathrm{N}-\mathrm{S}$, NE-SW, E-W and NW-SE directional trends. The results obtained have been evaluated using both an existing lineament map of the area and a field investigation. The high degree of consistency between the suggested method and the existing tectonic map indicates that lineaments in the study area are largely topographic. Field validation confirmed these findings except in a few well defined situations.
\end{abstract}

\section{General Terms}

GIS, Lineaments

\section{Keywords}

Lineaments, LandsatTM, ASTERGDEM, Remote Sensing, Schistbelt

\section{INTRODUCTION}

Lineaments are the structural results of geomorphological and geological processes. These lineaments can form rivers, dry river beds, valleys, ridges, geological faults and fractures in mountain crests [44]. The study of lineaments can provide the opportunity of assessment of the hydrogeology, volcanic structures, tectonics and rich prospects of minerals in the concerned areas $[9,24,31,34,32,39,37,40]$. The information on the geological aspects can be captured by the satellite sensors, which can be derived and used by the geologists for lineament mapping [44, 26, 36, 18,]. Lineaments are extracted using aerial photographs and satellite imagery by visual interpretation and hand tracing manually [21].However, these can be detected and interpreted based on their reflected physiographic features as a result of the tonal change in contrast, pattern and textures. These methods are distinct as the extraction relies upon the experience of an interpreter. The automatic extraction method requires the powerful algorithm $[4,17,37,12,21]$ (Table 1). The required data for analyzing lineaments are available through satellite sensors as Radarsat, Aster, Landsat and Digital Elevation Model (DEM) [24, 26, 41].

Characterizing geological structures are made by the mapping of lineaments with the computer assistance by using the spatial and morphological filters [26, 44, 46, 23]. The satellite images representing reflectance and backscattering are used for lineament extraction. The lineaments may be man-made or natural; the man-made linear features consist of highways, urban boundaries and agricultural farms, whereas, natural lineaments are due to geological forms. The natural lineaments may be positive, as strike ridges and dykes, while, the negative includes joints and faults [37, 20,25].

Generally, satellite images representing reflectance and backscattering characteristics of the earth's surface in response to electromagnetic waves at various wavelengths are used for lineament extraction. The auto-extraction of lineaments depends upon the algorithm efficiency and information of the image [5]. In the digital image processing of satellite data, image quality is typically determined by the inherent noise level in the image. Randomness in nature and interaction of electromagnetic radiation with the terrain's surface are the major factors influencing the image information content apart from noise levels.

The purpose of lineament analysis is to improve the understanding of the faults and lineament zones and to establish the relationships between the remote sensing data with the geological settings in the area with low cost. The present paper examines the automatic extraction of lineaments with band merged Landsat TM and ASTERGDEM combined Shaded reliefs in schist belt region.

\section{STUDY AREA}

The present work is carried out in and around Chicknayakanahalli (13036'25'’N, $76035^{\prime} 49^{\prime}$ 'E) schist belt which forms the southern part of the main Chitradurga schist belt. The Chitradurga schist belt is exposed along a middle part of the Karnataka state with a north-north westerly physiographic trend and extends from Gadag in the north to Srirangapatna in the south for the length of $460 \mathrm{~km}$. The belt attains its maximum width of $40 \mathrm{~km}$ near Chitradurga. The rocks of this area belong to Bababudan and Chitradurga Groups representing metabasalt-quartzite, BIF,quartz-sericitechlorite schist, quartzite, carbonates,and $\mathrm{Mn}$ formations $[10,11,33,43,42,33]$ and Table 2, Figure 1.

\section{MATERIALS AND METHODS}

3.1. Data preprocessing

3.1.1. Landsat Thematic Mapper Preprocessing 
The Landsat TM of 30m data having six bands (1, 2,3,4,5 and 7) is used. As a first step of preprocessing of the image, the vegetation was suppressed by removing the vegetation spectral signature, using red and near-infrared bands. It helps in better interpretation of geological features. The vegetation suppression model calculates the relationship of each input bands with vegetation, which decorrelates the vegetative component of the total signal on a pixel- by-pixel basis of each individual bands. The six bands are merged using mergeband that lets merge and recombine multiple bands into a single image, which is used for LINE extraction.

\subsubsection{ASTERDGEM Preprocessing}

The ASTERGDEM of $30 \mathrm{~m}$ resolution in order to identify linear topographic feature from DEM, four shaded relief images were generated. The first step is the production of four shaded relief images with light sources coming from four different directions. The first shaded relief image created had a solar azimuth (Sun angle) of $0^{\circ}$, a solar elevation of $30^{\circ}$ and the ambient light setting is only a scaling factor in the image topographic program $[1,14]$. The other three shaded relief images were created with three contrasting illuminating directions $45^{\circ}, 90^{\circ}$ and $135^{\circ}$. The second step is to combine four shaded relief images to produce one shaded relief image which leads to enhanced lineaments within the four Sun azimuth directions. For this purpose, the combinations of four shaded relief maps are computed by using Band Math. Where the four shaded relief images are combined to produce one image with multi - illumination directions $\left(0^{\circ}, 45^{\circ}, 90^{\circ}\right.$ and $135^{\circ}$ ) (Figure 2).

\subsection{Satellite image Lineaments Extraction}

The extraction of Lineaments for linear geologic and topographic features from all bands of Landsat TM and ASTERGDEM the Laplacian filtering technique is applied to enhance structures in the images. The lineament extraction algorithm of PCI Geomatica 2010 software was used which consists of edge detection, thresholding and linear extraction steps. The automatic lineament extraction process is carried out with LINE module of PCI Geomatica[29]. The LINE module of Geomatica extracts linear features of an image and records the polylines in a vector segment. LINE is controlled by the default parameters.

\subsubsection{Canny algorithm}

The automatic linear feature extraction is done with the use of optical images and DEM. Canny algorithm is used as an automatic lineament extractor with subsequent data processing in combination of edge detection, thresholding and curve extraction $[7,25]$ based on the Gaussian filter $[8,15$, 22]. It overcomes most of the limitations of Hough transformation and methods of edge detection [23, 26].

The algorithm of LINE (canny edge algorithm) consists of three stages viz. edge detection, thresholding and curve extraction. In the first stage, the Canny edge detection algorithm is useful to produce an edge strength image. The first step of Canny edge detection algorithm is processed by three sub-steps; first, the input image is filtered with a Gaussian function (Figure 3) whose radius is provided by the RADI (Filter Radius) parameter (Table 3 ). Then the gradient is computed from the filtered image. Finally, the pixels whose gradient are not a local maximum are suppressed by setting the edge strength to 0 .

In the second stage, the edge strength image is the threshold to obtain a binary image. Each pixel of the binary image represents an edge element. The threshold value is defined by the GTHR (Edge Gradient Threshold) parameter.

In the third stage, curves are extracted from the binary edge image. This step consists of several substeps. First, a thinning algorithm is applied to the binary edge image to produce pixel-wide skeleton curves. Then a sequence of pixels for each curve is extracted from the image. Any curve with a number of pixels less than the value of the LTHR (Curve Length Threshold) parameter is discarded from further processing.

\subsubsection{Lineament extraction and conversion vector segments}

There are several methods to detect the linear features and geomorphologic characteristics of the terrain. Here, an attempt is made to automatic lineament delineation, based on the edge enhancement followed by edge sharpening technique which gives the best result of lineaments. The extraction of lineaments is made using the LINE model (Canny algorithm) which takes an image channel as input. If the input channel is 16-bit or 32-bit, the image is first scaled to 8-bit using a nonlinear scaling routine. The output of LINE is a vector segment which contains linear features as extracted from the image [18]. The steps are carried out over the Landsat and ASTERGDEM image under default parameters.

The six parameters lineament maps RADI= Radius of Filter in pixels, GTHR $=$ Threshold for edge gradient, LTHR= Threshold for curve length, FTHR= Threshold for line fitting error, $\mathrm{ATHR}=$ Threshold for angular difference and DTHR= Threshold for linking distance [29,1] are generated using different threshold values. The most suitable thresholds are RADI $=10$, GTHR $=100$, LTHR $=30$, FTHR $=3, A T H R=30$, and $\mathrm{DTHR}=20$. RADI (Filter Radius) specifies the size of the Gaussian kernel used as a filter during edge detection. The larger the RADI value lesser the noise; and detail appear in the edge detection result. The value for thresholding the gradient image is defined by the GTHR (Edge Gradient Threshold) parameter [30]. The value is in the range of 0 to 255. It is experimented with different GTHR values and selected that produces suitable output binary image. When the ON pixels in the image seem sparse, the GTHR value is decreased. When the ON pixels appear dense and noisy the GTHR value is increased. Sufficient information in the edge image as the subsequent lineament extraction process is attained which is based on this edge image as input.

FTHR (Line Fitting Threshold) defines the tolerance for fitting line segments to a (curved) lineament. This value is specified in number of pixels. A lower value results in many shorter line segments, a larger value provides better noise averaging results in longer and straighter lineaments. Typically a value between 2 and 3 is ideal. LTHR (Curve Length Threshold) specifies the minimum length of a curve (in pixels) to be considered as lineament. ATHR (Angular Difference Threshold) defines the maximum angle (in degrees) between two vectors for them to be associated. DTHR (Linking Distance Threshold) specifies the maximum distance (in pixels) between two vectors for them to be associated. Several lineament maps are generated from Landsat bands and ASTERGDEM bands using different values. Based on the base map satellite image the Lineaments are digitized manually by interpretation keys and field experience. 


\section{RESULTS AND DISCUSSION}

\subsection{Line segments and Lineament Length}

The extracted lineaments show variations in length and frequency of occurrence of the line segments. The lineaments are attributed to the differences in spatial resolutions of the source data. The Landsat TM shows minimum length of $0.86 \mathrm{kms}$ and a maximum of $5.8 \mathrm{kms}$. ASTERGDEM delivered Shaded reprieves minimum length of $0.91 \mathrm{kms}$ and a maximum of $7.39 \mathrm{kms}$ (Table 4). The variations in the length and frequency of occurrence of the line segments and lineaments are attributed to the difference in spatial resolution and derived topography of the source data. Present work indicates occurrence of a wider and clear lineament. The maximum length of extracted lineament from ASTERGDEM is higher than Landsat TM extracted and visually interpreted lineaments and can be attributed to further studies related to mineralization, ground water studies, shear zones/faults and linear trends due to lithological layering. The Lineament extracted from the Landsat TM (Figure 4 (a)) is merged and the Lineament extracted from ASTERGDEM shows similar orientations, probably found in NW to SE directions (Figure 4 (b)).

\subsection{Lineament rose diagram analysis}

Lineaments mapped from Landsat TM and ASTERGDEM possess spatial variations in trend, frequency and length. The direction is analyzed using rose diagrams, which present the number of lineaments within angular classes of $15^{\circ}$. Rose diagrams are constructed from extraction and visually interpreted lineaments. Rose diagrams are constructed from extraction and visually interpreted lineaments. Here, the length of petals is proportional to the square of relative frequency to ensure equal area histograms. The ASTERGDEM extracted lineaments show major lineament directions in NNW-SSE i.e. from $315^{\circ}-360^{\circ}$. The total length for each orientation is similar when compared to the visually interpreted lineaments map. The minor petals in the rose diagram show orientation from $317^{\circ}-360^{\circ}$ i.e. NNW-SSE and NNE-SSW direction (Figure 5a). The Landsat TM extracted lineaments show major lineaments from NNW-SSE and minor from NNE-SSW i.e. $315^{\circ}-360^{\circ}$ and $0^{0}-60^{\circ}$ (Figure $5 \mathrm{~b}$ ). The major lineaments orientations are similarity in the long petals i.e. $330^{\circ}-360^{\circ}$ and differences in minor petals to visually interpreted lineaments and minor lineaments or petals in rose diagram are scattered over $360^{\circ}$. The automatic process of lineament extraction excludes the detection in developed areas such as urban areas or lands that were cleared for agricultural purposes.

\subsection{Lineament Density}

A lineament density map is another method to analyze the extracted lineament. The map is created by summing the lineament length available in a defined grid size. For practical reasons, the size of each grid was set to $100 \mathrm{mts}$ as a density map with a smaller grid size will take much longer time to be produced. Figure $6 \mathrm{a}$ shows the lineament numbers with a range varying from 0 to 15.45 . The dark part shows $>9$ and spread in NNW-SSE direction. Compared to the visual interpretation line density map, the density is more and Figure $6 \mathrm{~b}$ shows the lineament numbers with a range varying from 0 to 9.3, and the dark part shows 6 and spread in NNW-SSE direction. Compared to the visual interpretation line density map, the density is less. The density pattern of lineaments is a positive indicator for mineralization, and is one of the criteria for ore mineral occurrences in hydrothermal alteration zones (e.g. gold and copper) [31]. From an Engineering point of view these highly densed lineament zones are not suited for the construction of the dams as they have high trend for geohazards such as slope fails [31].

\section{CONCLUSION}

In this paper, an attempt has been made for mapping of lineaments and using remote sensing and GIS tools and techniques for the part of CNHalli schist belt. A methodology for lineament extraction provides quite satisfactory results for geological aspects of any developmental activity. Due to its multi-scale feature detection and representation ability, remote sensing technique is capable of extracting lineaments tendencies in the unreachable areas. It is suggested that the high lineament intersection density should be combined with the detailed survey for qualitative and quantitative geological analysis. This methodology might potentially be adopted for the identification of several features of geological and anthropological origin. The study results of lineaments rose diagram and density map of extracted lineaments can be applied to structural studies and their applications such as mineral exploration, ore-forming systems, nuclear energy facility settings, petroleum and ground water studies, water resource investigations.

\section{ACKNOWLEDGEMENTS}

This study is a part of the DST project ESS/16/321/2007 sanctioned to SAA.

\section{REFERENCES}

[1] Abdullah.A, Nassar.S, Ghaleeb.A, "Landsat ETM-7 for lineament mapping using automatic extraction technique in the SW part of Taiz area, Yemen", Global journal of human social science Geography, Geo-Sciences, Environmental and Disaster Management, 2013,13,3,3438 .

[2] Ahmed A, Madani, "Selection of the Optimum Landsat Thematic Mapping bands for automatic lineament extraction, Wadi natash area, South Eastern desert", Egypt. $22^{\text {nd }}$ Asian Conference on Remote Sensing, 2001, 5-9 November ,Singapore.

[3] Alaa Masoud, Katsuaki Koike, "Tectonic architecture through Landsat-7 ETM+/SRTM DEM- derived lineaments and relationship to the hydrogeologic setting in Siwa region, NW Egypt", Journal of African Earth Sciences, 2006, 45,467-477.

[4] Alaa- Masoud, Katsuaki Koike, "Auto-detection and integration of tectonically significant lineaments from SRTMDEM and remotely-sensed geophysical data", ISPRS journal of Photogrammetry and Remote sensing, 2011, 818-832.

[5] Al-Dossary, S and Marfurt, K.J, "Lineament-preserving filtering", Geophysics 72 (1) 2007, 1-8.

[6] Anwar Abdulla, Juhari Mat Akhir, Ibrahim Abdullah, "Automatic Mapping of Lineaments using shaded relief images derived from digital elevation model (DEMs) in the Maran-Sungi Lembing area", Malaysia, EJGE, 2010,15,948-957.

[7] Canny,J.F, "A computational approach to edge detection”, IEEE Trans.Pattern Anal. Mach. Intell 1986, $8(6), 679$.

[8] Chouhan, B, Shailja shukla, M.E. Sem, V.I., Jabalpur, J.E.C. Iris recognition system using canny edge detection 
for biometric identification. Inter. J. Eng. Sci. Technol. 2011, 3 (1), 31-35.

[9] Corgne.S, Magagi.R, Yergeau.M, Sylla.D, “An integrated approach to hydro-geological lineament mapping of a semi-arid region of West Africa using Radarsat-1 and GIS", Remote Sensing Environment, 2010, 114, 1863-1875.

[10] Devaraju.T.C, Anantha Murthy. K. S, "Iron and Manganese ores of Chiknayakanahalli schist belt, Tumkur District", Proceedings of Symposium Geology of ferrous and ferro-alloy minerals 1976, Bangalore1976, 1 to 10 .

[11] Devaraju.T.C, Anantha Murthy,K.S. Grunerite from Iron formations of CN Halli schist belt of Karnataka. Science Jour.Karnatak Univ, Sci.1977, 22, 99-109.

[12] Ehmann.W.J, "Lineaments and their association with metal deposits, Ruby Mountains, Montana", 1985, (200), 29, 85-599, MP.

[13] ENVI. User guide 2011, ENVI.

[14] ERDAS.Using ArcView Image Analysis1998, Atlanta: GA:ERDAS Inc.

[15] Heath.M, Sudeep.S, Thoma.S, Kevin.B, "Comparison of edge detectors, methodology and initial study", Comp. Vision Image Under, 1998, 69 (1), 38-54.

[16] Hobbs,W.H, "Lineaments of the Atlantic border region", Geological Society AmericanBulletin,1904;15:,483-506.

[17] Jordan. G, Schott.B, "Application of wavelet analysis to the study of spatial pattern of morphotectonic lineaments in digital terrain models:a case study", Remote Sensing of Environment,2005, 94, 31-38.

[18] Kocal.A, Duzgun.H.S, Ksrpuz.C, "Discontinuity mapping with automatic lineament extraction from high resolution satellite imagery", $20^{\text {th }}$ ISPRS Congress Technical Commission VII, Istanbul, Turkey, July 12-23, 2004, Editor; Orhan Altan.

[19] Kuntz,N, 2006. Canny Tutorial. www.pages.drexel.edu/ nk752/cannyTut2.html.(accesse d on 06-06-2013).

[20] Leech.D.P,Treloar.P.J,Lucas. N.S, Grocott, "Landsat TM analysis of fracture patterns: a case study from the Coastal Cordillera of northern Chile", International Journal of Remote Sensing, 2003, 24, 3709-3726.

[21] Leary.D.W,Friedman.J.D, Pohn. H.A, "Lineament, linear, lineation: some proposed new standard for old term", Geological Society AmericanBulletin,1976, 87, $1463-1469$

[22] Lijun. D,Ardeshir, G, " On the Canny edge detector", Pattern Recogn,2001, 34 (3), 721-725

[23] Mondal, T,Jain. A, Sardana,H.K, “Automatic craniofacial structure detection on cephalometric images", IEEE Trans. Image Proc.2011, 20 (9), 26062614.

[24] Masoud.A, Koike,K, "Auto-detection and integration of tectonically significant lineaments from SRTM DEM and remotely-sensed geophysical data", ISPRS Journal of Photogrammetry and Remote Sensing,2011, 66, 818832.
[25] Marghany.M,Hashim.M, "Developing adaptive algorithm for automatic detection of geological linear feature using RADARSAT-1SARdata", International Journal of the Physical Sciences, 2010, 5(Nov(14)),2223-2229.

[26] Mazlan Hashim, Samsudin Ahmad Md. Johari, Amin Beranvand Pour, "Automatic Lineament extraction in a heavily vegetated region using Landsat Enhanced Thematic Mapper (ETM+) imagery", Advances in Space Research,2013,51, 874-890.

[27] Morris.K, "Using knowledge-base rules to map the threedimensional nature of geologic features", Photogrammetric Engineering \& Remote Sensing.1991,57 (9),1209-1216.

[28] O'leary,D.W,Friedman.J. D,Pohn.H, “A Lineament, linear, lineation: some proposed new standards for old terms", Geological Society America Bulletin,1976, Vol.87,pp.1463-1469.

[29] PCI Geolmatica, manual., 2010.

[30] Prasad.A.D,Jain.K, Gairola, "Mapping of Lineaments and knowledge base preparations using geomatics techniques for part of the Godavari and Tapi Basins, India:A case study", International Journal of Computer Applications,2013, 70, 9,39-47.

[31] Pour.B.A,Hashim.M, "Identifying areas of high economic-potential copper mineralization using ASTER data in Urumieh-Dokhtar Volcanic Belt. Iran" Adv Space Res, 2012, 49, 753-769.

[32] Qari.M.H.T,Madani.A.A，Matsah. M.I.M，Hamimi，Z, "Utilization of ASTER and Landsat data in geologic mapping of basement rocks of Arafat area, Saudi Arabia”, Arabian J. Sci. Eng, 2012, 33, 99-116.

[33] Radhakrishna,B.P, "Reconsideration of some problems in the Archaean complex of Mysore", Journal Geological Society of India,1967, 18, 102-110.

[34] Ramadan,T.M,Abdel Fattah,M.F, "Characterization of gold mineralization in Garin Hawal area, Kebbi State, NW Nigeria, using remote sensing", Egyptian J. Remote Sens. Space Sci,2010, 13, 153-163.

[35] Ramakrishnan.M,Vaidynandhan.R, "Geology of India", Vol.1. Geological Society of India,2008, Bangalore, 556.

[36] Ramli.M.F,Yusoff.N,Juahir.H,Shafri.H.Z.M, "Lineament mapping and its application in landslide hazard assessment: a review", Bull Eng. Geol. Environ,2010, 69, $215-233$.

[37] Ranganai.R.T,Ebinger.C.J, "Aeromagnetic and Landsat TM structural interpretation for identifying regional groundwater exploration targets, south-central Zimbabwe Craton", J. Appl. Geophysics, 2008, 65, 73-83.

[38] Raj.K.G, "Origin and significance of hemavathi Tirthahalli mega lineament - A concept", Geosci. Remote Sens. Symp,1989, 1, 112-115.

[39] Rajesh.H.M, "Mapping Proterozoic unconformity-related uranium deposits in the Rockhole area, Northern Territory, Australia using Landsat ETM+", Ore Geo. Rev,2008,33, 382-396.

[40] Roy.R,Cassard.D,Cobbold.P.R,Rossello,E.A,Billa,M,Bai 1ly,L,Lips.A.L.W, "Predictive mapping for copper-gold 
magmatic-hydrothermal systems in NW Argentina: Use of a regional-scale GIS, application of an expert-guided data-driven approach, and comparison with results from a continental-scale GIS”, Ore Geo. Rev, 2006 29, 260286.

[41] Samuel Corgne, Ramata magagi, Michel Yergeau, Daouda Sylla, "An integrated approach to hydrogeological lineaments mapping of semi- arid region of West Africa using Radarsat-1 and GIS", Remote Sensing of Environment,2010, 114,1863-1875.

[42] Seshadri.T.S,Chaudari.P,Hainadha Babu, Chayapathi.N, "Chitraduga Schist belt. In: Swami Nath, J and Ramakrishana, M (Eds). Early Precambrian supracrustal of southern Karnataka", Mem. Geol. Surv. India Memoir,1981, 112,163-198.

[43] Srinivasan.R,Sreenivas.B.L, "A reappraisal of some aspects of the geology of Dhawars of Mysore state", India. Geol. Surv. India Misc, 1975, 23, 49-69.
[44] Soto-Ponto.C, Arellano-Baeza.A,Sanchez,G, “A new code for the automatic detection and analysis of lineament pattern for geophysical and geological purposes (ADALGEO)", Computers \& Geosciences,2013 57, 93-103.

[45] Suzen.M.L, Toprak.V, "Filtering of satellite images in geological lineament analyses: an application to a fault zone in Central Turkey”, International Journal of Remote Sensing 2008, 19 (6), 1101-1114.

[46] Tjia,H.D, "Major Fault of Peninsular Malaysia on Remotely-Sensed Images, In Sains Malaysiana,1989, 101-114.

[47] Tripathi.N,Gokhale.K,Siddique.M, "Directional morphological image transforms for lineament extraction from remotely sensed images", International Journal of Remote Sensing, 2000, 21 (17), 3281-3292.

Table 1.Comparison between the automatic and visual methods for lineament extraction

\begin{tabular}{|l|l|}
\hline Digital Analysis and Automatic Extraction Process & Visual Inspection and Extraction Process \\
\hline Highly depends only on the image quality ( soft copy) & $\begin{array}{l}\text { Highly depends on the quality of the image and its } \\
\text { printed hardcopy (softcopy and hard copy) }\end{array}$ \\
\hline Completely depends on the complexity of study area & Partially depends on the complexity of the study area \\
\hline Efficiency depends on software and process used & $\begin{array}{l}\text { Efficiency depends on a person's knowledge, skill and } \\
\text { experience }\end{array}$ \\
\hline $\begin{array}{l}\text { Consumes very less time and cheap when compared to } \\
\text { visual process }\end{array}$ & Time taking process and expensive \\
\hline $\begin{array}{l}\text { Distinguishing type of lineaments may be complex as } \\
\text { it includes anthropogenic alignments }\end{array}$ & Type of lineaments can be distinguished easily \\
\hline Complex but objective method & Simple but subjective method \\
\hline
\end{tabular}

Table 2. Stratigraphic Sequence of CN Halli Schist Belt, after Anantha Murthy (1980)

\begin{tabular}{|c|c|c|c|}
\hline & Later Intrusives: & \multicolumn{2}{|r|}{ Represented by Dolerite dykes } \\
\hline \multirow{8}{*}{ 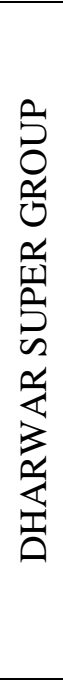 } & \multirow{6}{*}{ CHITRADURGA GROUP } & \multirow{6}{*}{ 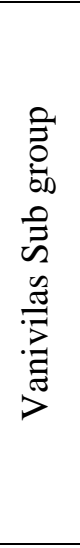 } & $\begin{array}{l}\text { Metabasic sills and flows - Amphibolite } \\
\text { Varieties }\end{array}$ \\
\hline & & & $\begin{array}{l}\text { Banded Iron formations - oxide, silicate, } \\
\text { carbonate and sulfide facies. }\end{array}$ \\
\hline & & & $\begin{array}{l}\text { Carbonates- Limestone, dolomite and } \\
\text { ferrodolomite }\end{array}$ \\
\hline & & & $\begin{array}{l}\text { Argillites - chlorite schist, sericite- chlorite } \\
\text { schist, garnet ferrous chlorite - schist and } \\
\text { quartz - actinolite - carbonate schist. }\end{array}$ \\
\hline & & & $\begin{array}{l}\text { Arenites - Sericite quartzite, sericite- } \\
\text { fuchsite quartzite, fuchsite quartzite }\end{array}$ \\
\hline & & & Arkosic - Paragneisses \\
\hline & 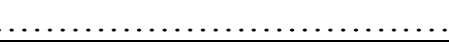 & con & (1, \\
\hline & BABABUDAN GRC & & $\begin{array}{l}\text { Metabasalt-Quartzite succession with minor } \\
\text { BIF of Kibbanahalli }\end{array}$ \\
\hline & & & \\
\hline
\end{tabular}


Table 3.Name and description

\begin{tabular}{|l|l|}
\hline Name & \multicolumn{1}{|c|}{ Description } \\
\hline RADI & Radius of filter in pixels \\
\hline GTHR & Threshold for edge gradient \\
\hline LTHR & Threshold for curve length \\
\hline FTHR & $\begin{array}{l}\text { FTHR Threshold for line fitting } \\
\text { error }\end{array}$ \\
\hline ATHR & Threshold for angular difference \\
\hline DTHR & Threshold for linking distance \\
\hline
\end{tabular}

Table 4.Line segments and Lineament Length

\begin{tabular}{|l|r|r|r|}
\hline & \multicolumn{1}{|l|}{$\begin{array}{l}\text { Landsat } \\
\text { TM }\end{array}$} & ASTERGDEM & \multicolumn{1}{l|}{ Manual } \\
\hline No. of Lineaments & 199 & 459 & 1063 \\
\hline Min. length $(\mathrm{km})$ & 0.86 & 0.91 & 1 \\
\hline Max. Length $(\mathrm{km})$ & 5.8 & 7.39 & 5.8 \\
\hline Total length $(\mathrm{km})$ & 268.055 & 836.24 & 552.04 \\
\hline
\end{tabular}

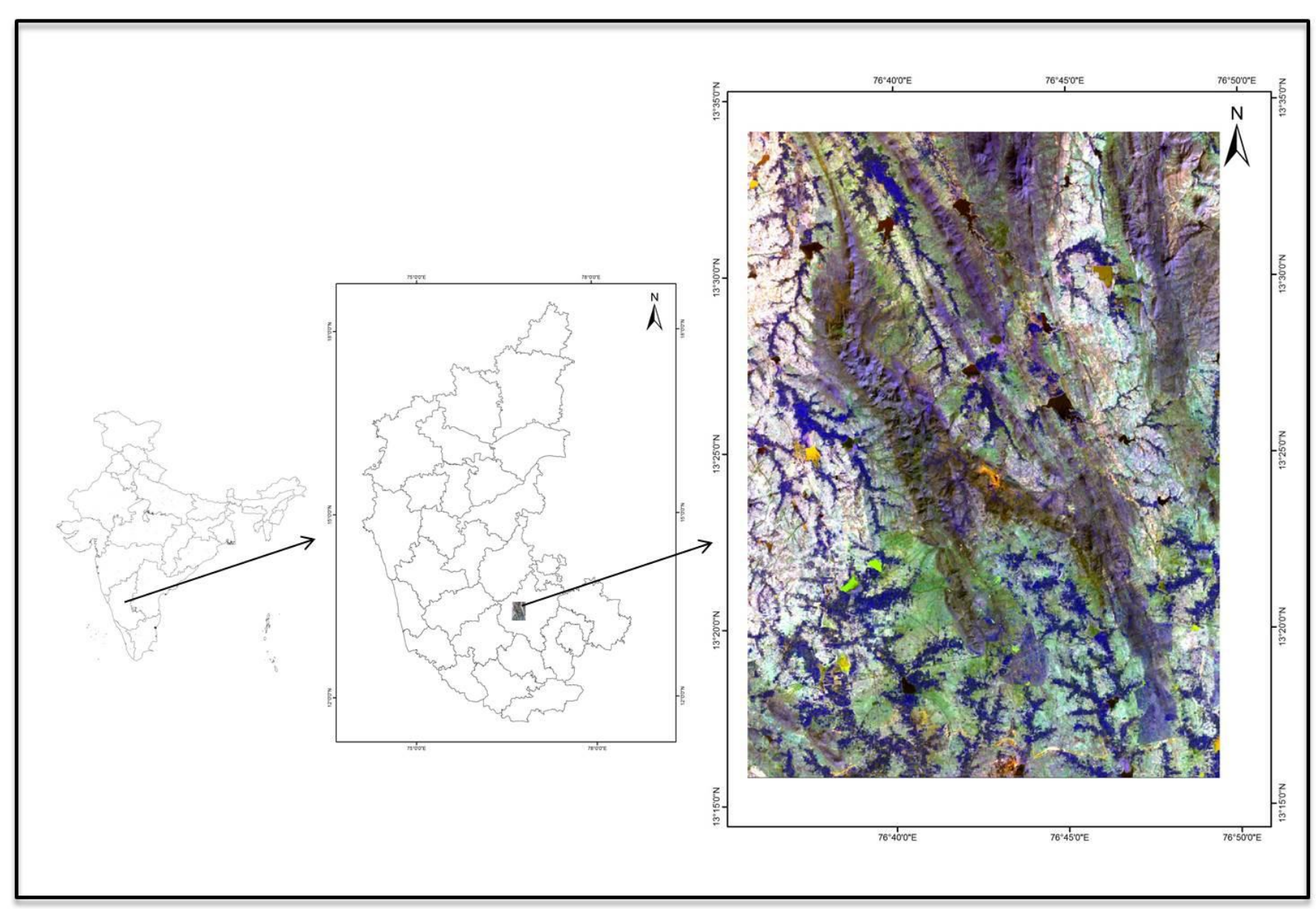

Figure 1: Location of the Study area 


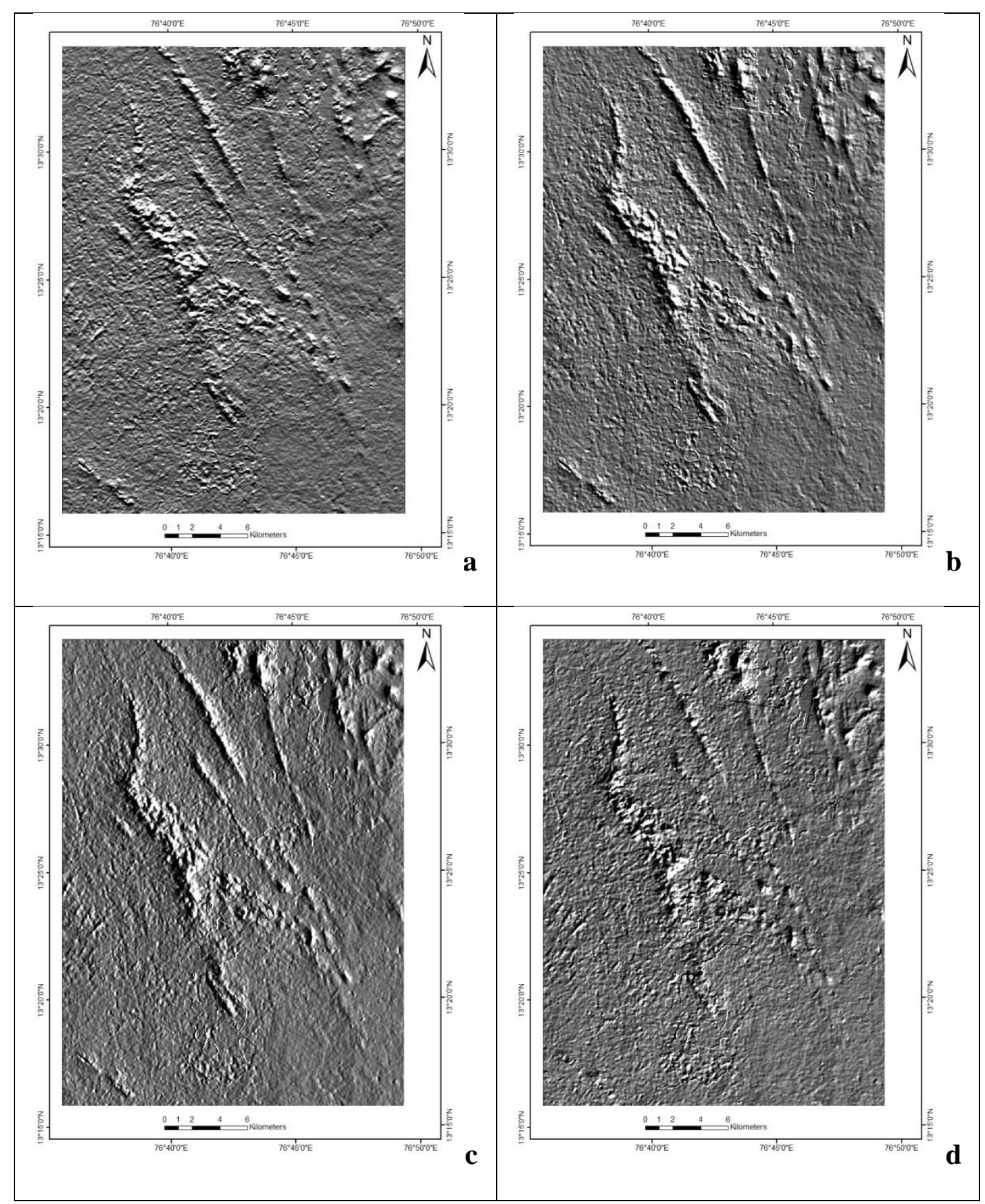

Figure 2: Shaded Relief of ASTERGDEM (a).Shaded Relief Map of $0^{\circ}(\mathrm{b})$. Shaded Relief Map of $45^{0}(\mathrm{c})$. Shaded Relief Map of $90^{0}$ (d). Shaded Relief Map of $135^{\circ}$

\begin{tabular}{|l|r|r|r|r|r|}
\hline \multirow{2}{*}{1} & 4 & 5 & 4 & 2 \\
\hline 4 & 9 & 12 & 9 & 4 \\
\hline 5 & 12 & 15 & 12 & 5 \\
\hline 4 & 9 & 12 & 9 & 4 \\
\hline 2 & 4 & 5 & 4 & 2 \\
\hline
\end{tabular}


Figure 3:Gaussian mask [19]

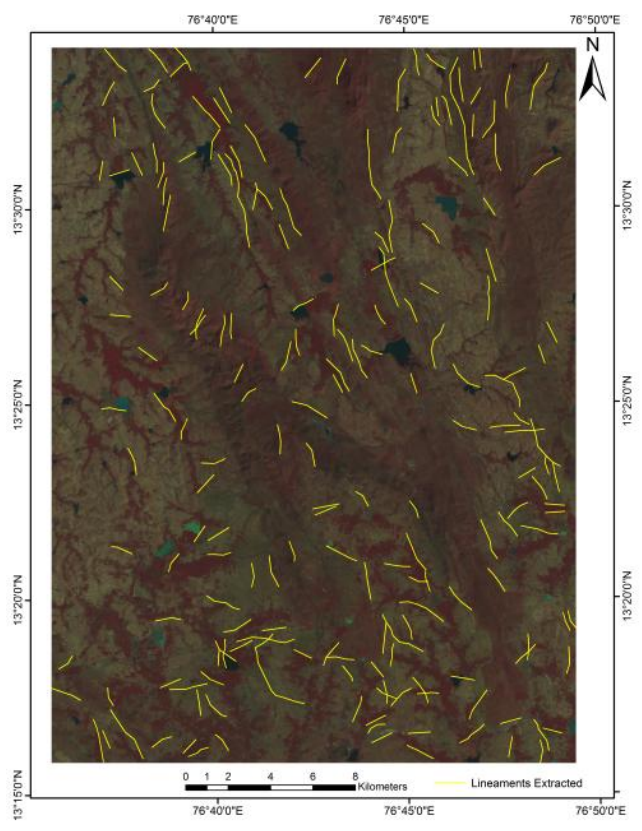

(a)

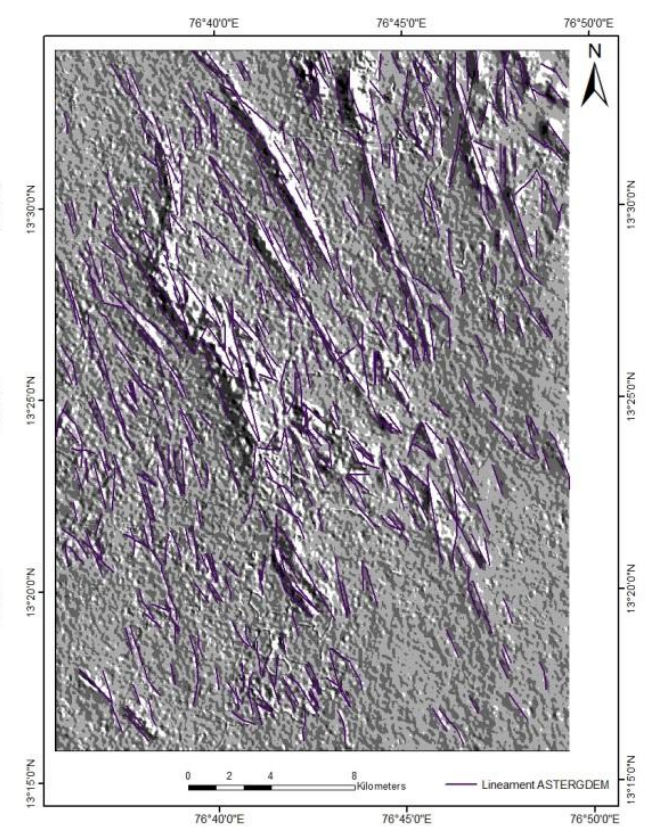

(b)

Figure 4.(a): Lineament Extracted from Landsat Image (b). Lineament Extracted from Combined Shaded Relief of ASTERGDEM

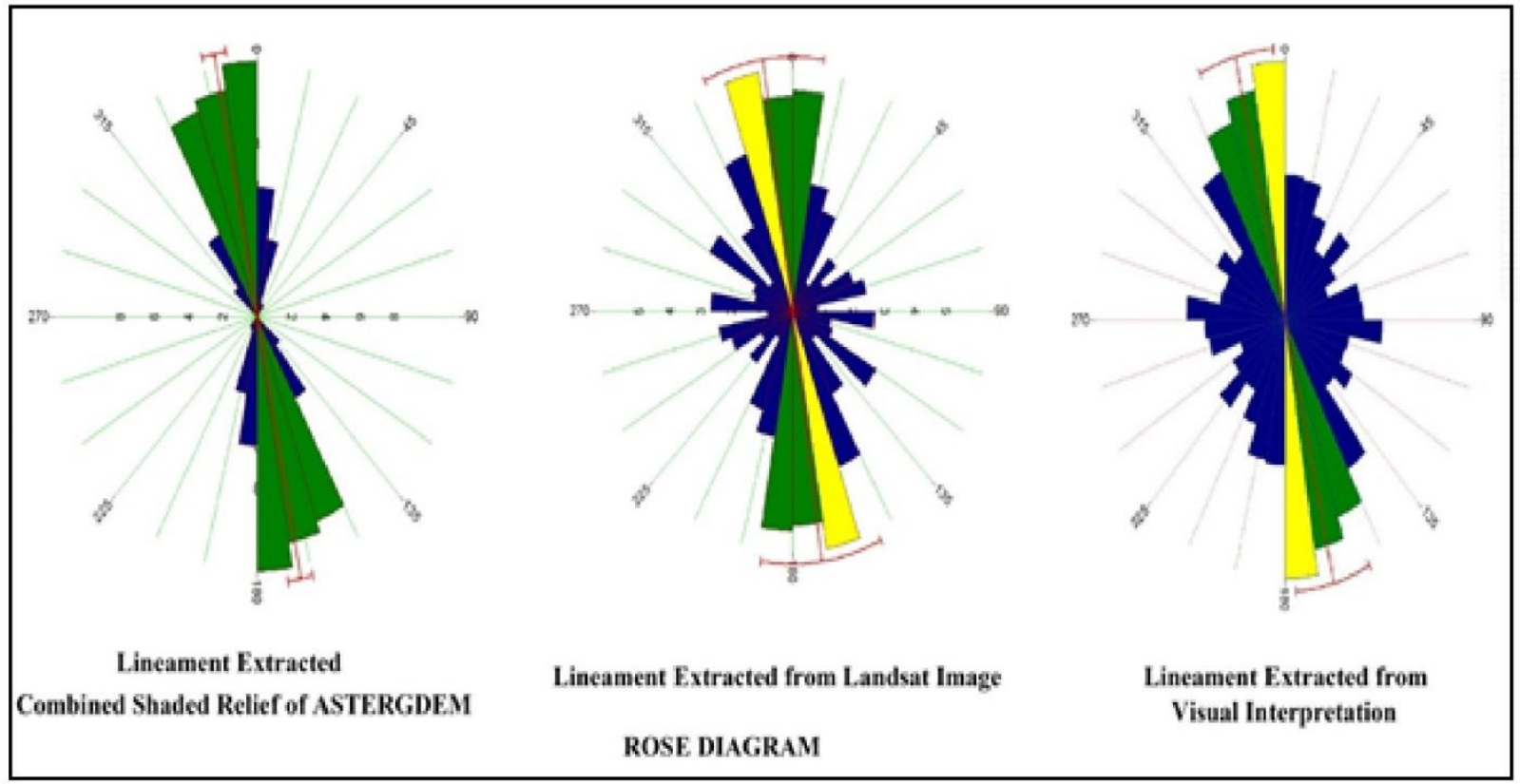

Figure5: Rose Diagram for the Extracted Lineaments a. from ASTERGDEM b. from Landsat Image c. Visual Interpretation 


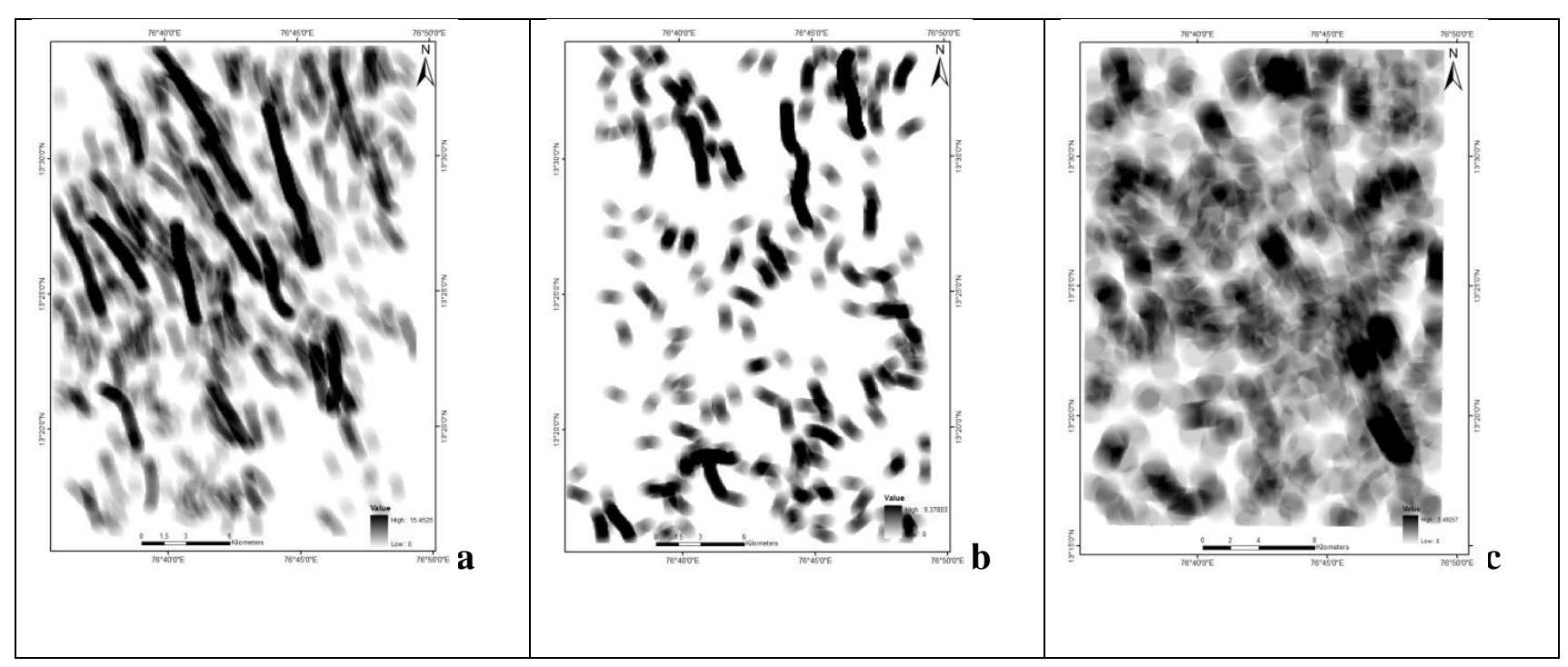

Figure 6: Line Density for Lineament Extracted from a. ASTERGDEM b. Landsat TM c. Visual Interpretation 